\title{
Primary urethral carcinoma - unexpected cause of urethral stricture. Case report and review of the literature.
}

\author{
Jakub Krukowski', Mateusz Czajkowski', Jakub Kłącz', Olga Wawrzaszek², Martyna

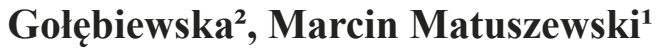

${ }^{1}$ Department of Urology, ${ }^{2}$ Student research group at the Department of Urology, Medical University of Gdańsk, Gdańsk, Poland

\begin{abstract}
Primary cancer of urethra (PCU) is one of rarest malignancies of the urinary tract. In early stages this type of cancer presents non specific symptoms which can be mistaken with more common urethral strictures. That is why the PCU is frequently recognize in a locally advanced stage. The basic tool used in the diagnosis is MRI, but ultrasonography can be also used at the beginning of diagnosis. We present the case of 66-year old patient with PCU, initially diagnosed due to urethral stricture. We report probably the first case of well documented sonourethrography findings in PCU.
\end{abstract}

Keywords: urethral cancer; sonourethrography; ultrasonography; urethral stricture

\section{Introduction}

Primary carcinoma of the urethra (PCU) is considered to be one of the rarest malignancies of the urogenital tract [1]. The incidence rate is estimated at 1.1 per 1 million inhabitants and is peaked after 75 years of age [2-4].

The manifestation of developing carcinoma is nonspecific and can be erroneously assigned to other obstructive disorders of the lower urinary tract. [5]. Haematuria and symptoms associated with lower urinary tract obstruction are most commonly reported by patients. Other symptoms include extraurethral mass, irritative

Received 05.05.2018 Accepted 14.07.2019

Med Ultrason

2019, Vol. 21, No 4, 494-496

Corresponding author: Jakub Krukowski, MD

Department of Urology, Medical University of Gdańsk, Gdańsk, Poland,

Smoluchowskiego 17 St., 80-952,

Gdańsk, Poland

E-mail: jakub.i.krukowski@gmail.com symptoms and pelvic pain [3,5-7]. In men, the most common localisation is bulbar urethra (59\%), followed by the penile urethra (33\%) and prostatic urethra (7\%) [8].

\section{Case report}

A 66-year old patient presenting with reduced urinary flow accompanied by abdominal straining, sensation of incomplete bladder emptying and post-micturition dribble, was admitted to the urology clinic. Two months prior the patient had undergone circumcision. Histopathological examination of the prepuce revealed lesions resembling lichen sclerosus (LS).

Physical examination revealed major stricture of the external urethral orifice, LS lesions on glans penis and firm, painless perineal mass in location corresponding to the bulbar part of the urethra. Upon examination, numerous palpable, enlarged, firm, movable and painless lymph nodes in both groins were revealed.

To evaluate the urethra and lesions in perineum, sonourethrography (SUG) was conducted using the modified 
McAninch technique $[9,10]$. Ultrasound examination showed a $35 \mathrm{~mm}$ stricture in the urethra located in the glans penis and an extensive pathological mass extending from the bulbar part of urethra towards the pelvic diaphragm (fig 1). The structure had a heterogeneous construction, with increased flows in Colour Doppler interrogation (CD). From the ventral side, the tumour boundary ended on the lamina of the corpus spongiosum, with no clear traits of crossing it. From the dorsal side, the tumour had an uneven border between the corpus spongiosum and corpora cavernosa, which could correspond to the infiltration of the cavernous bodies. Ultrasound of groins detected pathologically enlarged lymph nodes, with the loss of the hilar architecture. No pathological structures and metastatic changes in other organs were found in the abdominal ultrasound.

Additional imaging examinations were performed to extend the diagnostics. Both cystourethrography (CUG) (fig 2) and magnetic resonance (MRI) (fig 3a) confirmed the presence of the primary tumour within the bulbomembranous urethra. In MRI, inguinal nodes, in opposition to physical examination and US, did not represent features of metastatic nodes. Abdominal and chest CT did not reveal evident distant metastasis. No abnormal cells were found in the urine cytology.

Subsequently, the patient underwent an ureteroscopy with biopsy of a peripheral part of the urethral mass (fig $3 b)$. Due to the locally advanced mass obstructing the lumen, control of the posterior urethra and bladder was not possible. A suprapubic cystostomy was performed to relieve urinary retention. Histopathological examination of obtained material detected urothelial cell carcinoma mixed with squamous differentiation. Sentinel node biopsy confirmed metastasis to inguinal nodes. Initial clinical staging was established as cT3N2M0.

The case was brought up for discussion within a multidisciplinary team consisting of urologists, oncologists and radiologists. Neoadjuvant radiochemotherapy followed by a surgical procedure was established as a therapeutic plan. At the time of describing this case study, the patient is undergoing neoadjuvant treatment.

\section{Discussions}

In the urethral lumen there are three types of urothelium: transitional epithelium (prostatic urethra, pseudostratified columnar epithelium (membranous, bulbar and penile urethra) and stratified squamous epithelium (fossa navicularis and meatus) [11]. The lymphatic drainage occurs via two pathways depending on the part of the male urethra. Anterior part (bulbar and penile) is drained by lymphatic vessels into the superficial and deep ingui- nal nodes towards the pelvis, and the posterior urethra (prostatic and membranous) is drained into the presacral and internal iliac lymph nodes towards the pelvic nodes [12].

PCU had been classified according to WHO as urothelial (UCC), squamous (SCC) and adenocarcinoma (AC) of either unspecified or enteric type, with the remaining being extremely rare clear cell and adenoid cystic carcinomas [13]. UCC is the most frequent PCU, but most

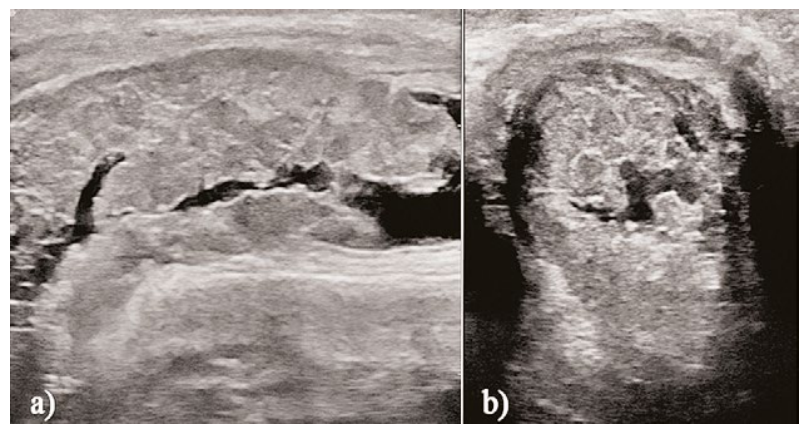

Fig 1. Sonourethrography. Pathological mass in the urethral lumen: a) longitudinal section; b) cross section.

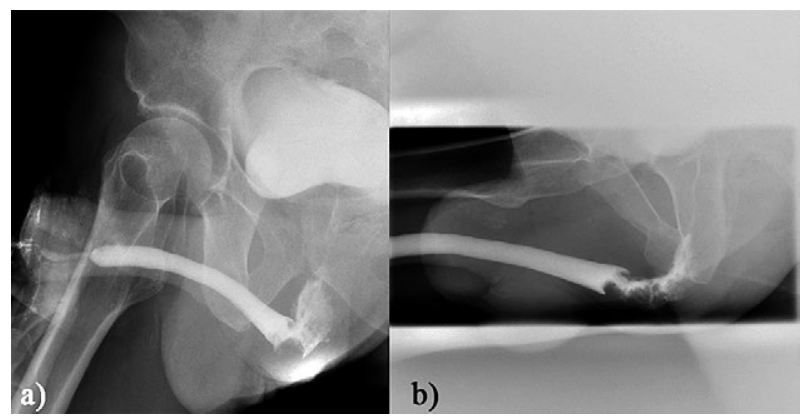

Fig 2. Cystourethrography: a) view on all anterior urethra. In the glans of the penis the urethral stricture is visible, and in the bulbar urethra the stricture is caused by the tumor; b) view focused on the bulbar urethra.

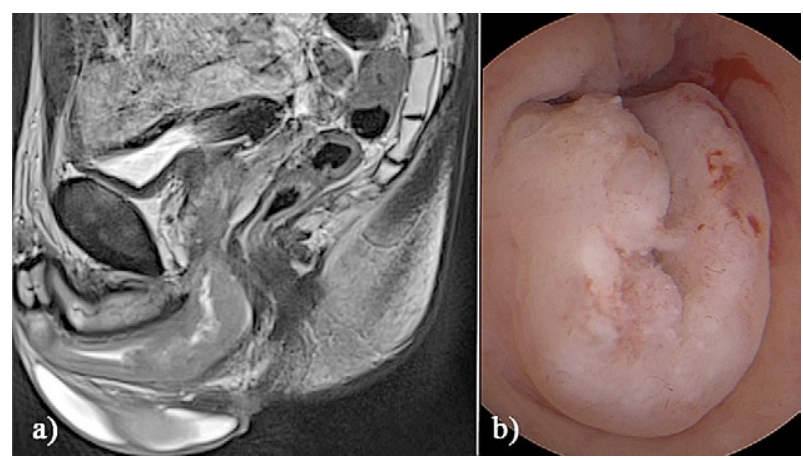

Fig 3. a) MRI of pelvis. In the bulbomembranous urethra the urethral tumor is visible, infiltrating the pelvic membrane and prostatic apex (T2-weighted image); b) Intraoperative image (view on tumor margin from the side of the urethral meatus). 
of the described PCU present with mixed urothelial and squamous differentiation $[3,14]$.

Prostatic urethra is affected mainly by UCC, and bulbomembranous and penile urethra by SCC. AC (arising from the Littré or Cowper glands) grows mainly in the bulbar urethra [15].

The imaging procedures that can be applied in the diagnostics are CUG, US, and MRI, with MRI being the most relevant $[16,17]$. Taking the described case into consideration, the role of US should not be disregarded. US is accessible, fast and can be conducted as pointof-care testing: hence it can constitute as a primary examination enabling diagnosis and launching of treatment procedures. So far, ultrasound features of PCU have not been described.

Based on our experience, we can conclude that the tumor in the US image shows the following features: hypoechoic (in comparison to corpus spongiosum), heterogenous structure; irregular borders; abrupt, shelflike margins (in contrast to the narrowing of the urethra caused by spongiofibrosis); and increased vascularity visible in the CD.

Currently, there is no consensus on PCU treatment. Treatment is adjusted individually to the patient in most cases, depending on the localisation, histology and staging of carcinoma. PCU is generally diagnosed in the locally advanced stage, hence treatment requires combination surgery depending on the histological subtype, radiotherapy or radiochemotherapy [18]. Inguinal lymphadenectomy is indicated only in patients with palpable lymph nodes, because their involvement in patients with $\mathrm{cN} 0$ is only $9 \%$. Patients with $\mathrm{cN}+$ inguinal lymphadenectomy are associated with improved overall survival [19].

\section{References}

1. Amin MB, Young RH. Primary carcinoma of urethra. Semin Diagn Pathol 1997;14:147-160.

2. Visser O, Adolfsson J, Rossi S, et al. The RARECARE working group. Incidence and survival of rare urogenital cancers in Europe. Eur J Cancer 2012;48:456464.

3. Zhang M, Adeniran AJ, Vikram R, et al. Carcinoma of urethra. Hum Pathol 2018;72:35-44.
4. Swartz MA, Porter PM, Lin DW, Weiss NS. Incidence of primary urethral carcinoma in United State. Urology 2006;68:1164-1168.

5. Dalbagani G, Zhang ZF, Lacombe L, Herr HW. Male urethral carcinoma: analysis of treatment outcome. Urology 1999;53:1126-1132.

6. Gheiler EL, Tefilli MV, Tiguert R, de Oliveira JG, Pontes JE, Wood DP Jr. Management of primary urethral cancer. Urology 1998;52:487-493.

7. Torbrand C, Håkansson U, Ehrnström R, Liedberg F. Diagnosing Distal Urethral Carcinomas in Men Might Be Only the Tip of the Iceberg. Clin Genitourin Cancer 2017;15:e1131-e1135.

8. DayyaniF,Hoffman K,EifelP, etal.Managementofadvanced primary urethral carcinomas. BJU Int 2014;114:25-31.

9. McAninch JW, Laing FC, Jeffrey RB Jr. Sonourethrography in evaluation of urethral stricture: preliminary report. J Urol 1988;139:294-297.

10. Krukowski J, Kałużny A, Matuszewski M. Can ultrasonography be useful in the diagnosis of urethral disorders of female-to-male transsexuals? Med Ultrason 2019. doi:10.11152/mu-1908.

11. Orlandini SZ, Orlandini GE. Ultrastructure of human Male urethra. Arch Androl 1989;23:51-59.

12. Caroll PR, Dixon CM. Surgical anatomy of the male and female urethra. Urol Clin North Am 1992;19:339-346.

13. Moch H, Cubilla AL, Humphrey PA, Reuter VE, Ulbright TM. The 2016 WHO classification of tumors of the urinary system and male genital organs - part A: renal, penile, and testicular tumors. Eur Urol 2016;70:90-105.

14. Sui W, RoyChoudhury A, Wenske S, Decastro GJ, McKiernan JM, Anderson CB. Outcomes and prognostic factors of primary urethral cancer. Urology 2017;100:180-186.

15. Basiri A, Narouie B, Moghadasi MH, Ghasemi-Rad M, Valipour R. Primary Adenocarcinoma of the Urethra: A Case Report and Review of the Literature. J Endourol Case Rep 2015;1:75-77.

16. Sharma S, Agarwal N, Negi A, Makhaik S. Imaging features of carcinoma of male urethra. Ind J Radiol Imag 2006;16:905-906.

17. Stewart SB, Leder RA, Inman BA. Imaging tumors of the penis and urethra. Urol Clin North Am 2010;37:353-367.

18. Antwerpen I, Gstrein L, Moskovszky L. Primary urethral squamous cell carcinoma: a unique manifestation of penile tumor. J Int Med Res 2019;47:999-1004.

19. Werntz RP, Riedinger CB, Fantus RJ, et al. The role of inguinal lymph node dissection in men with urethral squamous cell carcinoma. Urol Oncol 2018;36:526.e1-526.e6. 